\title{
Evaluación de la virosis del achaparramiento de la alfalfa (Medicago sativa L.) en dos ambientes contrastantes de Argentina
}

\author{
Odorizzi, A. S., Cornacchione, M. V., Arolfo, V., Basigalup, D. H., Mijoevich, M. L. y Balzarini, M.
}

\begin{abstract}
RESUMEN
En los últimos años se vienen observando daños crecientes de una enfermedad viral que afecta la producción y la persistencia del cultivo de alfalfa en Argentina. El objetivo de este trabajo fue comparar la incidencia y severidad de la sintomatología de la enfermedad y explorar las relaciones de su dinámica con respecto a precipitaciones (pp) y temperaturas ( $T$ ) ambientales en seis cultivares comerciales de alfalfa durante el período 2010-2014. Los cultivares CW1010, WL1058, Traful PV INTA, WL903, Monarca SP INTA y LPS8500 fueron evaluados en los campos experimentales de la Estación Experimental Agropecuaria (EEA) Manfredi del Instituto Nacional de Tecnología Agropecuaria (INTA) y de la EEA Santiago del Estero-INTA. En ambos ensayos se registraron incidencias medias entre $50 \%$ y $80 \%$, con importante variabilidad interanual y diferencias entre cultivares. La severidad fue mayor para los cultivares evaluados en Santiago del Estero. Los cultivares WL903 y WL1058 presentaron menor severidad, mientras que LPS8500 y Monarca SP INTA presentaron los mayores valores. De las variables climáticas utilizadas para este análisis, la pp ( $p p$ + riego en Santiago del Estero) y la T máxima fueron las de mayor peso para explicar la incidencia de la enfermedad. Con respecto a la severidad, la variable que mayor explica su incremento es la T media.
\end{abstract}

Palabras clave: incidencia, severidad, virosis, Medicago sativa L.

Odorizzi, A. S., Cornacchione, M. V., Arolfo, V., Basigalup, D. H., Mijoevich, M. L. y Balzarini, M.,2017. Alfalfa dwarf disease evaluation (Medicago sativa L.) in two contrasting environments in Argentina. Agriscientia 34 (II): 69-81

\section{SUMMARY}

In the last years, it has been observed an increasing damage from a viral disease affecting the production and persistence of alfalfa in Argentina. The objective of this work was to compare the incidence and severity of the disease symptoms and to explore the relationship of its dynamics with respect to rainfall $(\mathrm{pp})$ and temperature $(\mathrm{T})$ in six commercial alfalfa cultivars during the period 2010-2014. The cultivars CW1010, WL1058, Traful PV INTA, WL903, Monarca SP INTA and LPS8500 were evaluated in trials at EEA Manfredi-INTA and at 
EEA Santiago del Estero-INTA. In both trials, mean incidences between 50\% and $80 \%$ were recorded, with significant interannual variability and differences among cultivars. The severity was higher for the cultivars evaluated in Santiago del Estero. Cultivars WL903 and WL1058 presented the lowest severity, while LPS8500 and Monarca SP INTA showed the highest values. As for the climatic variables used for this analysis, pp (pp + irrigation in Santiago del Estero) and maximum $T$ were the variables that mostly determined the incidence of the disease. Mean T was the most important variable regarding severity.

Key words: incidence, severity, viral infections, Medicago sativa L.

Odorizzi, A. S., Arolfo, V. y Basigalup, D. H. INTA-EEA Manfredi. Mejoramiento Genético de Alfalfa. RN No 9, km 636, 5988, Manfredi, Córdoba, Argentina. Tel: (54) 3572-493053, fax: (54) 3572-49306. Cornacchione, M. V. y Mijoevich, M. L. INTA-EEA Santiago del Estero. Jujuy 850, 4200, Santiago del Estero, Santiago del Estero, Argentina. Balzarini, M. Cátedra Estadística, FCA-UNC. CC 509, 5000, Córdoba, Argentina. Correspondencia a: odorizzi.ariel@inta.gob.ar

\section{INTRODUCCIÓN}

La alfalfa (Medicago sativa L.) es la principal especie forrajera cultivada en Argentina, con amplia distribución debido a su gran adaptación a las distintas zonas productivas. En el país se reportaron cerca de veinte enfermedades que afectan al cultivo con diverso grado de importancia según regiones (Gieco, Moreno y Basigalup, 2007). Desde hace una década aproximadamente, se observan en Argentina y Uruguay daños crecientes por una enfermedad de origen viral que causa achaparramiento (gran disminución en la altura de las plantas), amarillamiento de las nervaduras y severa deformación de hojas, que incluye arrugamiento, epinastia y engrosamiento de las nervaduras en el envés de los folíolos, originando enaciones y formaciones tipo papilas de distintos tamaños. Todo esto afecta significativamente la producción y, más aún, la persistencia del cultivo. Esta enfermedad comenzó a notarse por deformaciones generalmente sobre las nervaduras principales y con menor frecuencia en las laterales en los folíolos, que se presentaban como arrugados y a veces con excreciones histoideas que aparecían en el envés de las hojas, notándose también un mosaico internerval (Lenardón, Basigalup y Pérez Fernández, 2010). Una enfermedad viral con síntomas similares a los observados en nuestro país fue descripta en 1959 en Rumania (Blattny, 1959) y, a comienzos de la década de 1970 en Francia y España, donde se caracterizó la morfología de la partícula viral, las alteraciones ultraestructurales inducidas y se estudiaron algunos aspectos epidemiológicos. Esta enfermedad estaba ocasionada por el Alfalfa enation virus (AEV), miembro tentativo de la familia Rhabdoviridae (Alliot y Signoret, 1972; Alliot, Giannotti y Signoret, 1972; Signoret, Alliot y Leclant, 1971; Leclant, Alliot y Signoret, 1973; Rodríguez Sardiña y Novales Lafarga, 1973). Esta enfermedad se presentó luego en Arabia Saudita, donde además se encontró la presencia de enaciones, una menor tasa de crecimiento, pérdidas en los rendimientos y cambios en la coloración de plantas, en las que se observó una infección doble entre Alfalfa mosaic virus (AMV) y AEV (Cook y Wilton, 1984; Marble, 1989).

Existen antecedentes de la aparición de estos síntomas en cultivos de alfalfa en la zona de riego del Río Dulce en Santiago del Estero desde el año 2008. En diferentes ambientes donde se cultiva alfalfa, sometidos a distintos manejos y condiciones hídricas (secano y con riego), se estimó una prevalencia a nivel del cultivo superior al $90 \%$ (Lenardón et al., 2010). Relevamientos realizados por los autores del presente trabajo pertenecientes al grupo de Mejoramiento Genético de Alfalfa del Instituto Nacional de Tecnología Agropecuaria (INTA), Estación Experimental Agropecuaria (EEA) Manfredi, Córdoba, entre los meses de enero y abril de 2010 en alfalfares en el área rural de Villa María (Córdoba), determinaron una incidencia de la enfermedad del $52 \%$ y una pérdida promedio del rendimiento en materia seca del $54,4 \%$.

En el análisis realizado a todas las plantas de alfalfa que presentaban síntomas de la 
enfermedad, y que fueron recolectadas en distintas zonas productoras de Argentina, se identificaron cinco virus: el AMV (Trucco, de Breuil, Bejerman, Lenardón y Giolitti, 2014), el Alfalfa dwarf virus (ADV) (Bejerman et al., 2011; Bejerman et al., 2015), el Bean leafroll virus (BLRV) (Trucco et al., 2016), el Alfalfa enamovirus 1 (AEV-1) (Bejerman et al., 2016) y el Alfalfa leaf curl virus (ALCV) (Bejerman et al, 2017).

Las enfermedades causadas por virus incluyen variadas interacciones entre planta-virus-vector, que a su vez están influenciadas por las condiciones ambientales sobre cada uno de ellos (Jones, 2014). Como los síntomas son alteraciones del metabolismo de la planta ocasionadas por uno o varios virus y, a su vez, esta reacción depende del estadio fisiológico de la planta (determinada en parte por la edad, la nutrición, el clima, etc.), se espera que los síntomas sean muy variables. Así, existen virosis con síntomas progresivos que causan un debilitamiento general, como el decaimiento inducido por el virus de la tristeza de los cítricos (CTV) ( Bar-Joseph, Marcus y Lee, 1989), hasta virosis donde la infección y la multiplicación de los virus no producen síntomas visibles, pudiendo estar latente o en período de incubación (Stakman y Harrar, 1968). Otras veces, los síntomas pueden desaparecer temporalmente, fenómeno que se conoce como enmascaramiento (Smith, 1972). Factores como la temperatura y la intensidad de la luz pueden inducir cambios en la severidad de los síntomas o enmascararlos temporalmente, como sucede con el virus del enanismo del ciruelo (Prune dwarf virus), en el cual la enfermedad se enmascara con temperaturas superiores a $13{ }^{\circ} \mathrm{C}$ (Pontis Videla, 1975).

La mayoría de los virus necesitan un agente vivo como vector de transmisión, como pueden ser los áfidos, chicharritas, moscas blancas, coleópteros y trips, u otros vectores tales como hongos, nemátodos, ácaros y plantas parásitas (Mena Adriano y Ríos, 2010). Los pulgones constituyen el grupo más importante de vectores, ya que transmiten alrededor del $60 \%$ de los virus transmitidos por insectos (Raman, 1986). Cuando un pulgón llega a una planta, realiza inserciones de su estilete o piquetes. El piquete de probado, de corta duración, es el responsable de la adquisición e inoculación de virus del tipo no-persistentes. El piquete de alimentación, aunque depende del tiempo en el que el vector este picando, se encarga de la transmisión de virus de tipo persistentes (Mena Adriano y Ríos, 2010). Del complejo de virus causantes del achaparramiento de la alfalfa encontrados hasta el presente, solo el AMV se transmite de manera no-persistente; el resto de los virus del complejo pertenecen a grupos virales que lo hacen de manera semipersistente o persistente (Trucco, com. pers.). En la planta, una vez que ingresa el virus, la infección se mantiene durante todo el ciclo de cultivo, fluctuando la sintomatología y carga viral (Pontis Videla, 1975).

Se conocen aproximadamente diez especies de pulgones que colonizan cultivos de alfalfa. Seis de ellas están presentes en Argentina, de las cuales cuatro son consideradas plagas: Aphis craccivora - Aphis laburni (pulgón negro de las leguminosas), Acyrthosiphon kondoi Shinji (pulgón azul de la alfalfa), Acyrthosiphon pisum Harris (pulgón verde) y Therioaphis trifolii Monnell (pulgón manchado). Delgado Enguita y Calvo (1992) mencionaron al pulgón negro de las leguminosas como el vector responsable de la transmisión de una enfermedad de estas características en España. Este pulgón se registró por primera vez en cultivos de alfalfa de Argentina en 1985. Es un pulgón de color verde oscuro casi negro, opaco ceroso en las ninfas y negro brillante en los adultos, de unos $2 \mathrm{~mm}$ de longitud, que forma colonias muy densas sobre el tercio superior de los tallos (Aragón e Imwinkelried, 2007).

Los objetivos de este trabajo fueron: a) aportar información sobre esta enfermedad viral poco conocida, ya que en el continente americano no se han descripto previamente síntomas similares en alfalfa; b) comparar la incidencia y severidad de la sintomatología de la enfermedad en cultivares comerciales de alfalfa sin reposo invernal (GRI 8-10); y c) estudiar la dinámica de la enfermedad respecto de precipitaciones y temperatura en dos localidades de Argentina.

Los datos aportados por este trabajo son la primera evaluación a campo sobre variedades comerciales de la enfermedad causada por la virosis del achaparramiento de la alfalfa, ampliamente difundida en Argentina.

\section{MATERIALES Y MÉTODOS}

\section{Área de estudio}

El estudio se llevó a cabo en dos campos experimentales de INTA. Un ensayo estuvo localizado en la EEA Manfredi, $31^{\circ} 49^{\prime} 12^{\prime \prime} \mathrm{S}$, $63^{\circ} 46^{\prime} 00^{\prime \prime} \mathrm{O}$ y a $292 \mathrm{~m}$ s.n.m. y otro en el campo experimental Francisco Cantos de la EEA Santiago del Estero (EEASE), 28 $01^{\prime} 00^{\prime \prime} \mathrm{S}, 64^{\circ} 13^{\prime} 00^{\prime \prime} \mathrm{O}$ y a 169 m s.n.m.

El clima de la EEA Manfredi se caracteriza por ser templado, con una precipitación (pp) media anual de $744 \mathrm{~mm}$, distribuidos según un régimen 
de tipo monzónico. En la EEA Manfredi el suelo está clasificado como Haplustol éntico (Serie Oncativo), profundo, bien drenado (INTA, 1987).

El clima de la EEA Santiago del Estero corresponde al tipo semiárido, sin ningún excedente de agua. La pp media anual es de 606 $\mathrm{mm}$, con una estacionalidad bien marcada de octubre a marzo. La evapotranspiración potencial es alta, resultando en un balance hídrico negativo para todos los meses del año. El suelo está clasificado como Haplustol torriorténtico de textura franco limosa (Serie La María), escaso desarrollo, bien drenado y con cierta acumulación de sales o carbonatos en profundidad (Angueira y Zamora, 2007).

\section{Diseño experimental}

Durante cuatro temporadas de crecimiento (2010-2014), se evaluaron seis cultivares (cv): Monarca SP INTA y LPS8500 de GRI 8, Traful PV INTA y WL903 de GRI 9 y CW1010 y WL1058 de GRI 10. El diseño experimental fue de bloques completos al azar (BCA) con cuatro repeticiones. Las parcelas en cada ensayo fueron de $5 \mathrm{~m}$ de largo y $1 \mathrm{~m}$ de ancho, con hileras distanciadas a $20 \mathrm{~cm}$ y una densidad de siembra de $20 \mathrm{~kg} \mathrm{ha}^{-1}$.

\section{Evaluación de la enfermedad}

La toma de muestras para determinar síntomas se realizó antes de cada corte de evaluación de biomasa, cuando la mayoría de las plantas alcanzaron el estadio 5 (floración temprana) según Kalu y Fick (1983). Las muestras se tomaron en una superficie prefijada de $20 \times 40 \mathrm{~cm}$ dentro de tres parcelas de $5 \mathrm{~m}^{2}$ por cultivar. La muestra fresca fue separada en tallos con síntomas y tallos asinto- máticos por evaluación visual, que se usaron para calcular la incidencia (I) de la sintomatología de la enfermedad. En este trabajo, la incidencia de la sintomatología será denominada "incidencia de la enfermedad" y se expresará en porcentaje (\%). La I fue registrada como el cociente entre la cantidad de tallos con síntomas y el total de tallos de la muestra multiplicado por 100. La misma fue evaluada en todos los cortes desde la primera hasta la tercera temporada de producción en Manfredi y hasta la cuarta temporada en Santiago del Estero.

Para evaluar la severidad de la enfermedad, se desarrolló una escala cualitativa basada en la cantidad y tipo de afectación de tejido en tallos y en las nervaduras de los folíolos (Tabla 1, Figuras 1 y 2).

Los grados de severidad se utilizaron para estimar el índice de severidad de la enfermedad (ISE expresado en porcentaje), de acuerdo a lo propuesto por Grau, Radke y Gillespie (1982). EI ISE se define como la sumatoria de la cantidad de tallos en cada grado de severidad multiplicada por el grado y dividida por el total de tallos de la muestra, multiplicado por el máximo grado:

ISE $=\sum_{i=0}^{3}\left(\frac{\text { grado } i \times n \text { de plantas en el grado } i}{n^{\circ} \text { total de plantas } \times 3}\right) \times 100$

Los valores de ISE pueden ir de 0 a 100, siendo este último valor el correspondiente a genotipos severamente afectados.

\section{Evaluación de la producción}

Para cada cultivar, se determinó la biomasa total de cada parcela $\left(5 \mathrm{~m}^{2}\right)$ en cada corte $\left(\mathrm{kg} \mathrm{MS} 5 \mathrm{~m}^{-2}\right.$ corte $^{-1}$ ) y con esos datos se calculó la producción media acumulada (t MS ha-1) de cada temporada de producción.

Tabla 1. Escala de severidad para evaluación del achaparramiento de la alfalfa.

\begin{tabular}{|c|c|c|c|}
\hline Grado & Tallo & Folíolo & Nervadura \\
\hline 0 & Normal & $\begin{array}{l}\text { Asintomático } \\
\text { Coloración: característica }\end{array}$ & Normal \\
\hline 1 & Normal & $\begin{array}{l}\text { Enrulamiento: incipiente } \\
\text { Tamaño: levemente reducido } \\
\text { Coloración: cambio leve }\end{array}$ & Engrosamiento incipiente \\
\hline 2 & $\begin{array}{l}\text { Normal o con } \\
\text { acortamiento leve de } \\
\text { entrenudos }\end{array}$ & $\begin{array}{l}\text { Enrulamiento: evidente. } \\
\text { Tamaño: reducido } \\
\text { Coloración: cambio evidente }\end{array}$ & $\begin{array}{l}\text { Engrosamiento incipiente. } \\
\text { Con o sin enaciones, uña de gato }\end{array}$ \\
\hline 3 & $\begin{array}{l}\text { Acortamiento severo } \\
\text { de entrenudos }\end{array}$ & $\begin{array}{l}\text { Arrepollado } \\
\text { Tamaño: muy reducido } \\
\text { Coloración: mosaico con } \\
\text { amarillamiento del borde del folíolo }\end{array}$ & $\begin{array}{l}\text { Engrosamientos prominentes, } \\
\text { enaciones, uña de gato }\end{array}$ \\
\hline
\end{tabular}




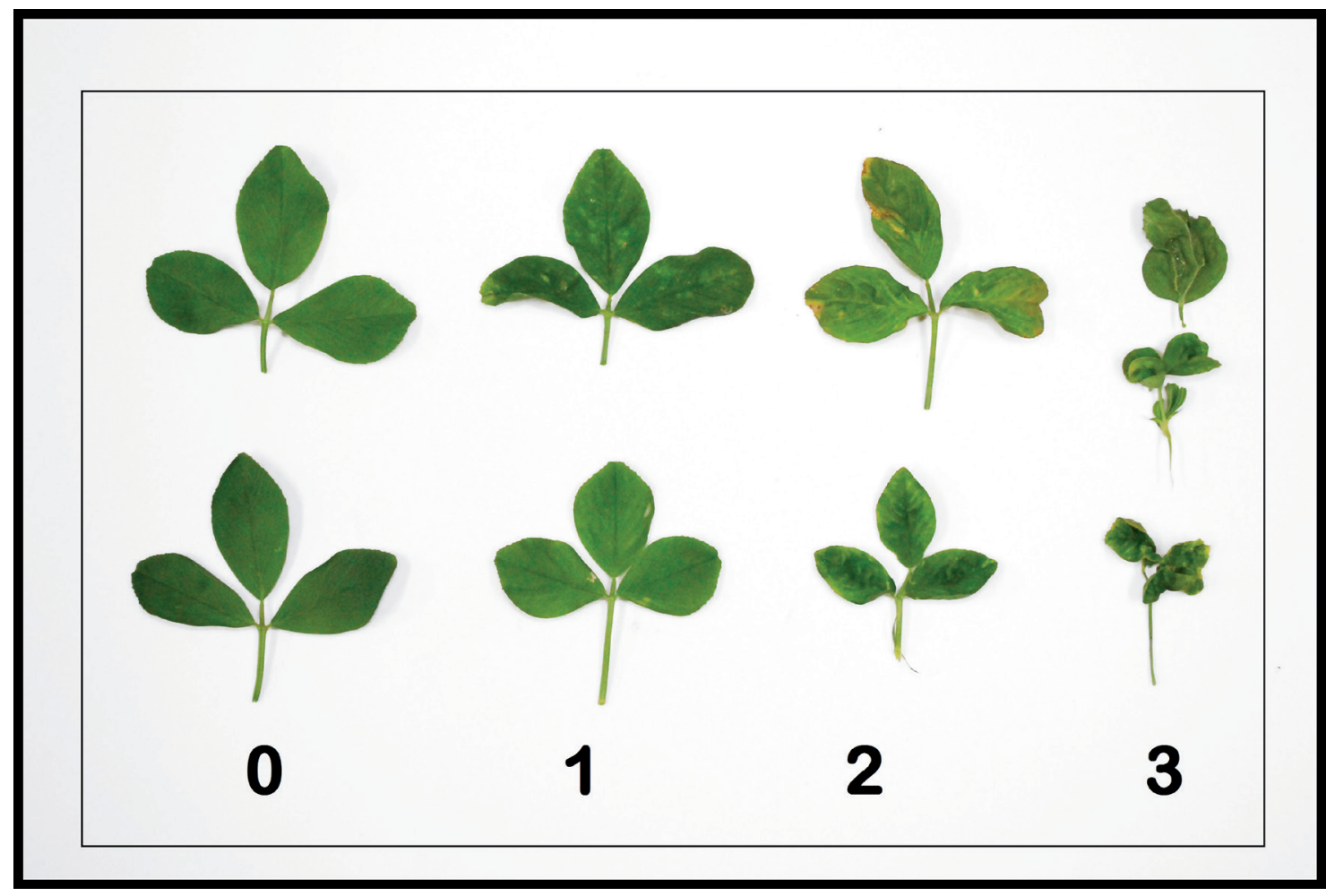

Figura 1. Escala de grados de severidad en folíolos de alfalfa.

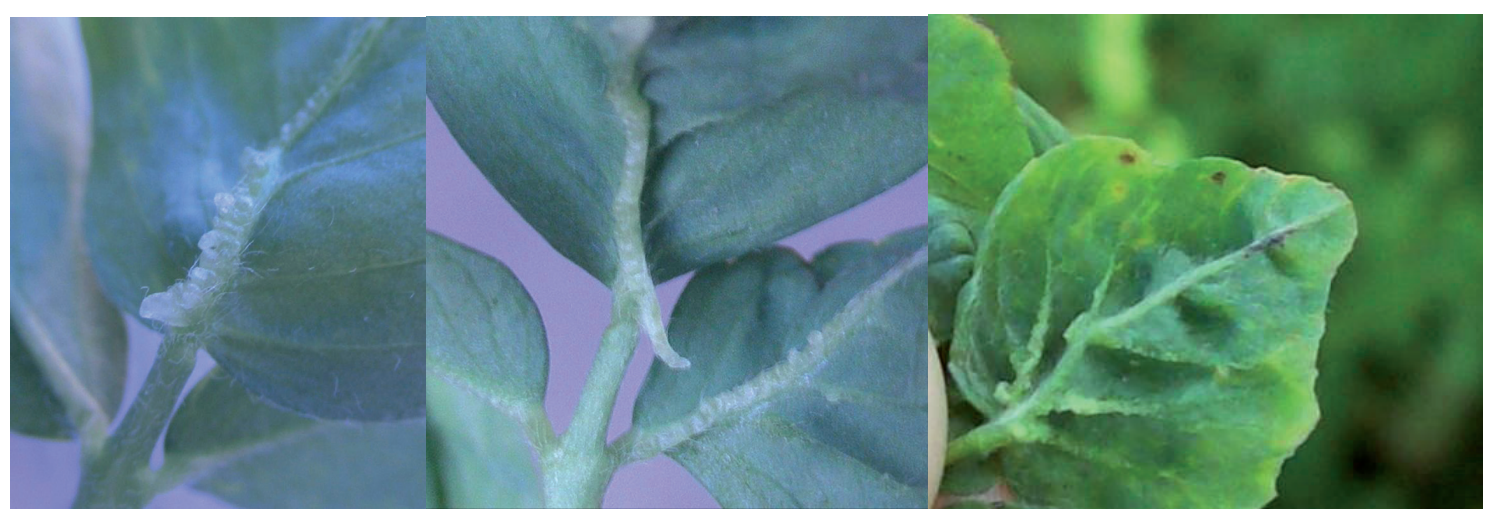

Figura 2. Detalles en folíolos de alfalfa con síntomas de grado 3 de severidad: a) enaciones o verrugas, solas o en rosario, ubicadas en la nervadura central en el envés de los folíolos; b) uñas de gato sobre la nervadura central generalmente en la unión del peciolulo y el folíolo; y c) nervaduras secundarias engrosadas con o sin presencia de verrugas.

\section{Evaluación ambiental y su relación con la sintomatología de la enfermedad}

Se registraron los datos climáticos de temperatura $\left(T^{\circ} \mathrm{C}\right)$ y precipitaciones $(\mathrm{pp})$ en cada localidad. En Santiago del Estero, atentos a que la alfalfa se realiza mayormente bajo riego, se adicionaron a las precipitaciones los aportes por riego a fin de estimar el total de agua recibida por el cultivo en cada ciclo de evaluación.

En cada sitio experimental y para la temporada en la cual se registraron los mayores porcentajes de I e ISE, se analizó la dinámica de la enfermedad en relación a las variables ambientales con las que se correlacionó la enfermedad. 


\section{Análisis de datos}

Los datos de I, ISE y biomasa aérea por localidad se analizaron usando el procedimiento de Modelos Mixtos Lineales del paquete estadístico InfoStat, versión 2013 (Di Rienzo et al., 2013). Diferencias significativas entre medias se identificaron mediante la prueba de comparaciones múltiples LSD Fisher con un nivel de significancia $p=0,05$. Con el fin de conocer cuáles fueron las variables climáticas regresoras cuyos valores umbrales explicaran mejor la incidencia y la severidad, se construyeron árboles de clasificación a partir de todo el conjunto de datos obtenidos para ambas localidades. Para una mejor visualización, los resultados obtenidos a partir de los árboles de clasificación se muestran en gráficos de barra.
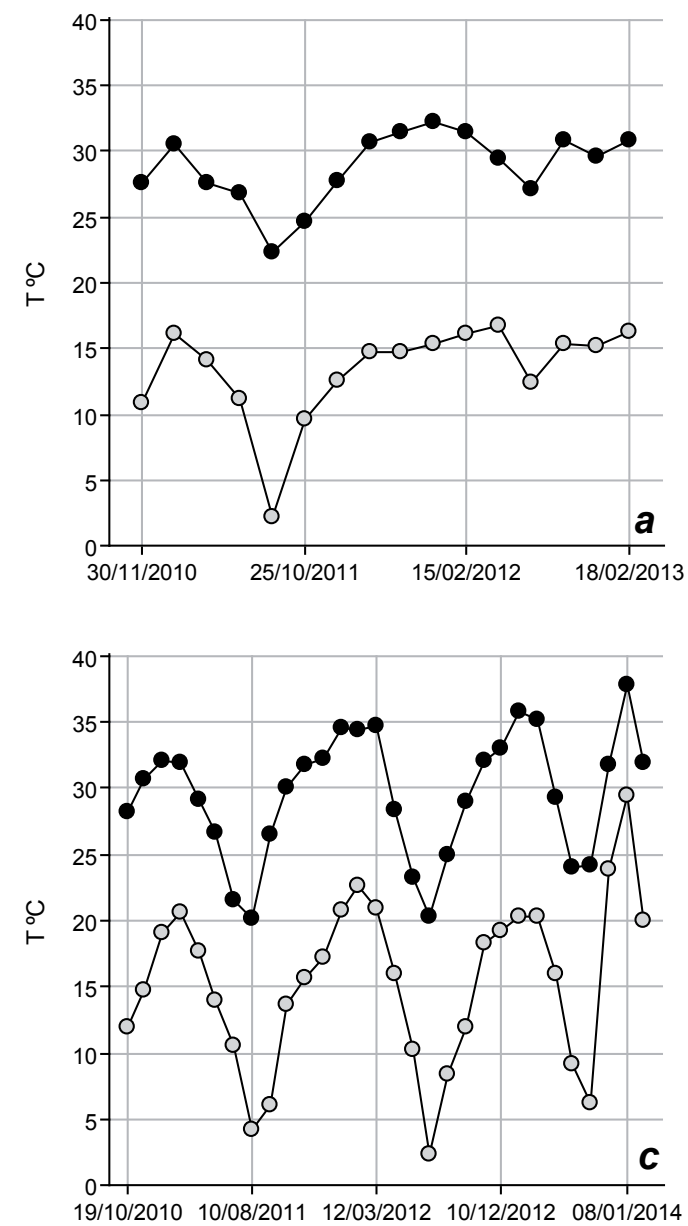

\section{RESULTADOSY DISCUSIÓN}

\section{Datos meteorológicos}

Se registraron los datos de temperatura máxima (Tmax) y mínima (Tmin) en ${ }^{\circ} \mathrm{C}$ y pp en mm para las tres temporadas de producción en Manfredi (Figura 3, a y b) y las cuatro en Santiago del Estero (Figura 3, c y d).

\section{Incidencia y severidad de la enfermedad en ambas localidades}

En la Tabla 2 se presentan las estimaciones de I e ISE para los seis cultivares de alfalfa, según las evaluaciones de la enfermedad en cada localidad. En la EEA Manfredi se evaluaron tres de las cuatro
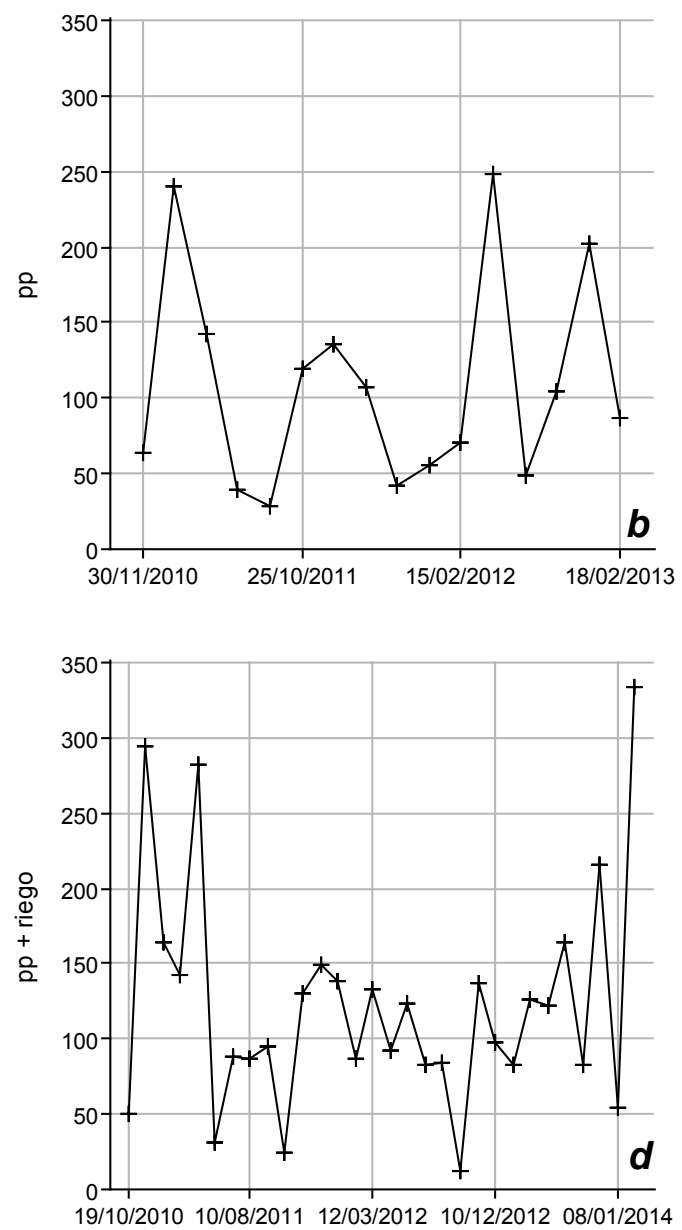

Figura 3. Temperaturas máxima y mínima y precipitaciones durante el período 2010-2013 en Manfredi (a y b) y 2010-2014 en Santiago del Estero (c y d). Referencias: Tmax, O Tmin, + pp y pp + riego. 
temporadas previstas, debido a la baja o nula persistencia de la alfalfa observada en las parcelas al finalizar el tercer invierno.

La evolución de la I de la enfermedad presentó variaciones según temporada, localidad y cultivar, aunque se observó una tendencia clara a incrementarse con la edad de las plantas. La I media general fue cercana al $51 \%$ en Manfredi y superior al $80 \%$ en Santiago del Estero. Al ser esta enfermedad sistémica causada por un complejo de virus que necesariamente requieren de un vector para su transmisión (Mena Adriano y Ríos, 2010), la alta I registrada evidenció la susceptibilidad del cultivo al vector responsable de la transmisión de la enfermedad (Bejerman et al., 2011; Trucco et al, 2014., Bejerman et al., 2015, Trucco et al., 2016, Bejerman et al., 2016). Al carácter complejo per se de esta enfermedad, ocasionada por infecciones multivirales, se suma la naturaleza perenne de la alfalfa, que la convierte simultáneamente en hospedante y reservorio de los virus del achaparramiento. En Manfredi, los valores de I mínimo y máximo correspondieron al cv LPS8500 durante la primera y segunda temporada, respectivamente. En Santiagodel Estero, la mínima I se registró en Traful PV INTA y la máxima en Monarca SP INTA, en todas las temporadas. Los valores de I exhibieron una importante variabilidad entre cortes (datos no mostrados). Esto podría estar relacionado con la remoción periódica de la parte aérea que se hace en cada corte, lo que podría ocasionar que las yemas que rebrotan posteriormente puedan no contener la misma carga viral que el material removido. Según Jones (2016), las variaciones de temperaturas a lo largo del año podrían ser las responsables de las tasas de multiplicación y el movimiento individual de cada virus en una infección múltiple, lo que podría contribuir a las variaciones registradas.

En Manfredi, la media del ISE fue cercana al $30 \%$, con un rango de 17,44 a $39,70 \%$. Los cultivares WL903 y WL1058 fueron los menos afectados, mientras que LPS8500 fue el más afectado, seguido por Monarca SP INTA.

En Santiago del Estero, los valores máximos de ISE Ilegaron a $87,89 \%$, claramente mayores a los observados en Manfredi. El cultivar WL903 fue el menos afectado con ISE significativamente menor al de Monarca SP INTA y LPS8500 en tres temporadas. Monarca SP INTA fue el cultivar más severamente afectado, mostrando severidad creciente a lo largo de las temporadas. En Santiago del Estero los cultivares de GRI 8 tendieron a verse más afectados que los cultivares de GRI 9 y 10. Los mayores valores de I e ISE se presentaron durante la segunda temporada (2011-2012) en Manfredi y la tercera temporada (2012-2013) en Santiago del Estero.

Como fuera expresado anteriormente, en Santiago del Estero la incidencia de la enfermedad

Tabla 2. Medias de incidencia e índice de severidad para cada cultivar evaluado durante las temporadas productivas en las EEA Manfredi y Santiago del Estero.

\begin{tabular}{|c|c|c|c|c|c|c|c|}
\hline Localidad & Año & LPS $8500(8)^{\star \star}$ & $\begin{array}{c}\text { Monarca SP INTA } \\
\text { (8) }\end{array}$ & Traful PV INTA (9) & WL903 (9) & WL1058 (10) & CW1010 (10) \\
\hline & \multicolumn{7}{|c|}{ Incidencia (\%) } \\
\hline & 1 & $25,69 b$ & $43,43 a$ & $27,24 b$ & $37,49 a b$ & $38,85 a b$ & $38,19 a b$ \\
\hline \multirow[t]{3}{*}{ Manfredi } & 2 & $75,35 a$ & $65,17 a b$ & $61,73 a b$ & $57,05 b$ & $65,19 a b$ & $72,61 a$ \\
\hline & 3 & $60,12 a b$ & $51,67 a b c$ & $63,43 a$ & $45,91 b c$ & $40,97 c$ & $50,05 a b c$ \\
\hline & 1 & $47,39 a$ & $56,03 a$ & $29,29 a$ & $38,37 a$ & $34,56^{a}$ & $40,43 a$ \\
\hline \multirow{5}{*}{$\begin{array}{l}\text { Santiago del } \\
\text { Estero }\end{array}$} & 2 & $97,04 a b$ & $97,76 a$ & $91,01 c$ & $92,09 c$ & $93,40 b c$ & $92,07 c$ \\
\hline & 3 & $98,86 a$ & $100 a$ & $85,49 d$ & $92,24 c$ & $93,79 b c$ & $98,26 a b$ \\
\hline & 4 & $97,83 a b$ & $100 a$ & $86,83 c$ & $88,84 b c$ & $89,01 b c$ & $94,31 a b c$ \\
\hline & \multicolumn{7}{|c|}{ Índice de severidad (\%) } \\
\hline & 1 & $s / d$ & $s / d$ & $\mathrm{~s} / \mathrm{d}$ & $s / d$ & $s / d$ & $s / d$ \\
\hline \multirow[t]{3}{*}{ Manfredi } & 2 & $39,70^{a}$ & $34,20 b$ & $28,48 c d$ & $25,32 d$ & $29,73 b c d$ & $31,25 b c$ \\
\hline & 3 & $30,10^{a}$ & $22,64 a b c$ & $27,04 a b$ & $17,44 c$ & $18,22 b c$ & $21,98 a b c$ \\
\hline & 1 & $\mathrm{~s} / \mathrm{d}$ & $\mathrm{s} / \mathrm{d}$ & $s / d$ & $s / d$ & $\mathrm{~s} / \mathrm{d}$ & $s / d$ \\
\hline \multirow{3}{*}{$\begin{array}{l}\text { Santiago del } \\
\text { Estero }\end{array}$} & 2 & $65,04 b$ & $76,79 a$ & $56,26 c$ & $51,09 c$ & $52,68 c$ & $51,91 c$ \\
\hline & 3 & $67,87 b$ & $87,84 a$ & $56,32 c d$ & $51,13 d$ & $57,91 \mathrm{bcd}$ & $62,42 b c$ \\
\hline & 4 & $70,23 a b$ & $83,55 a$ & $54,43 c$ & $51,57 c$ & $56,86 b c$ & $58,35 b c$ \\
\hline
\end{tabular}

Año=temporadas productivas. 1=2010-2011; 2=2011-2012; 3=2012-2013 y 4=2013-2014.

** Grado de reposo invernal. Dentro de cada localidad, letras diferentes en fila indican diferencias significativas de acuerdo al test LSD Fisher $(p<0.05)$. 
fue superior y la severidad llegó a duplicar los valores registrados en la EEA Manfredi, lo que sugiere que la relación vector-virus-planta se agravó en este ambiente más cálido (Figura 3). En esta localidad, no solo las temperaturas máximas y mínimas fueron superiores a las registradas en Manfredi, sino que además se observó una tendencia creciente en los valores de las temperaturas máximas entre 2010 y 2014. El aporte hídrico también fue mayor en Santiago del Estero, que en conjunto con las mayores temperaturas propiciaron una mayor manifestación de la enfermedad con respecto a Manfredi.

\section{Producción de biomasa en ambas localidades}

La producción media de forraje por corte a lo largo de las temporadas se resume en la Tabla 3. Se detectaron diferencias estadísticamente significativas entre cultivares para cualquiera de las temporadas. Los mayores valores se registraron en Santiago del Estero por el efecto combinado del aporte hídrico y las temperaturas más altas.

El cv WL903 presentó los valores más bajos de producción de biomasa en todas las temporadas en la EEA Manfredi, mientras que el cv CW1010 se destacó como el de mayor producción por corte. El cv Monarca SP INTA registró la menor producción de biomasa en todas las temporadas en la EEA Santiago del Estero, siendo el cv WL1058 el que se destacó como el de mayor producción por corte en las temporadas 2, 3 y 4 .

\section{Relación conjunta de la incidencia y severidad con las variables climáticas}

Con el conjunto de datos provenientes de ambas localidades, se construyeron los árboles de clasificación que relacionan ambiente y enfermedad y cuyos resultados se muestran mediante gráficos de barras en las Figuras 4, 5 y 6, para una mejor interpretación de éstos. Entre los parámetros climáticos analizados, se observó que en primer lugar la pp (Santiago del Estero, pp+riego), y en segundo lugar la Tmax, fueron las variables regresoras que mejor explicaron la I de la enfermedad. Períodos entre cortes con valores de pp+riego entre 77 y $140 \mathrm{~mm}$ presentaron mayor I de la enfermedad (Figura 4). Por otro lado, períodos con Tmax por encima de los $31,3^{\circ} \mathrm{C}$ propiciaron una mayor I (Figura 5), sin dejar de mencionar que por debajo de esa temperatura también se evidenciaron altos valores de I.

La variable que mejor explicó el ISE fue la Tmed, ya que valores por encima de los $24^{\circ} \mathrm{C}$ propiciaron una mayor severidad de la enfermedad (Figura 6); y valores por debajo de $24{ }^{\circ} \mathrm{C}$ favorecieron la aparición de síntomas menos severos, con mayor frecuencia de grados 1 y 2 (ver Figura 1).

Las relaciones entre la multiplicación de los virus y los síntomas que causan (efectos visibles del patógeno sobre su hospedante), aún son poco entendidas aunque se sabe que dependen en gran medida de varios factores, como medio ambiente, relación virus-hospedante, condiciones fisiológicas de las plantas, edad de los tejidos del hospedante y tiempo de infección (Agrios, 2005).

Existen antecedentes que indican un efecto positivo del incremento de temperatura sobre la dinámica de la población de pulgones y el proceso de transmisión de virus (Van Baaren, Le Lann y Van Alphen, 2010). Si se considera que el pulgón negro podría ser el vector responsable de la transmisión de virus, los incrementos de temperatura podrían favorecer el aumento de las poblaciones de pulgones. A su vez, mayores temperaturas medias y ocurrencia de estrés calórico provocan un

Tabla 3. Biomasa promedio por corte según cultivar por localidad de evaluación y temporada de producción.

\begin{tabular}{lccccccc}
\hline Localidad & Año & LPS8500 (8)** Monarca SP INTA (8) Traful PV INTA (9) & WL903 (9) & WL1058 (10) & CW1010 (10) \\
\hline & & \multicolumn{7}{c}{ Biomasa (t MS ha ${ }^{-1}$ corte) } \\
\cline { 3 - 8 } Manfredi & 2 & $1,44 b$ & $1,44 b$ & $1,60 b$ & $1,20 c$ & $1,19 c$ & $2,03 a$ \\
& 3 & $1,22 b$ & $1,24 b$ & $0,97 b c$ & $0,74 c$ & $1,20 b$ & $1,70 a$ \\
\hline \multirow{2}{*}{ Santiago } & 1 & $2,48 c$ & $1,72 b$ & $1,72 b$ & $1,08 d$ & $1,66 b c$ & $2,43 a$ \\
del Estero & 2 & $2,78 a b$ & $2,21 b$ & $2,52 a$ & $2,69 a$ & $2,53 a$ & $2,52 a$ \\
& 3 & $2,90 b$ & $2,28 c$ & $2,67 a b$ & $2,89 a$ & $2,90 a$ & $2,61 b$ \\
& 4 & $2,07 a b$ & $1,42 c$ & $2,91 b$ & $2,92 b$ & $3,11 a$ & $2,82 b$ \\
\hline
\end{tabular}

Año=temporadas productivas. 1=2010-2011; 2=2011-2012; 3=2012-2013 y 4=2013-2014.

** Grado de reposo invernal. Dentro de cada localidad, letras diferentes en fila indican diferencias significativas de acuerdo al test LSD Fisher $(p<0.05)$. 


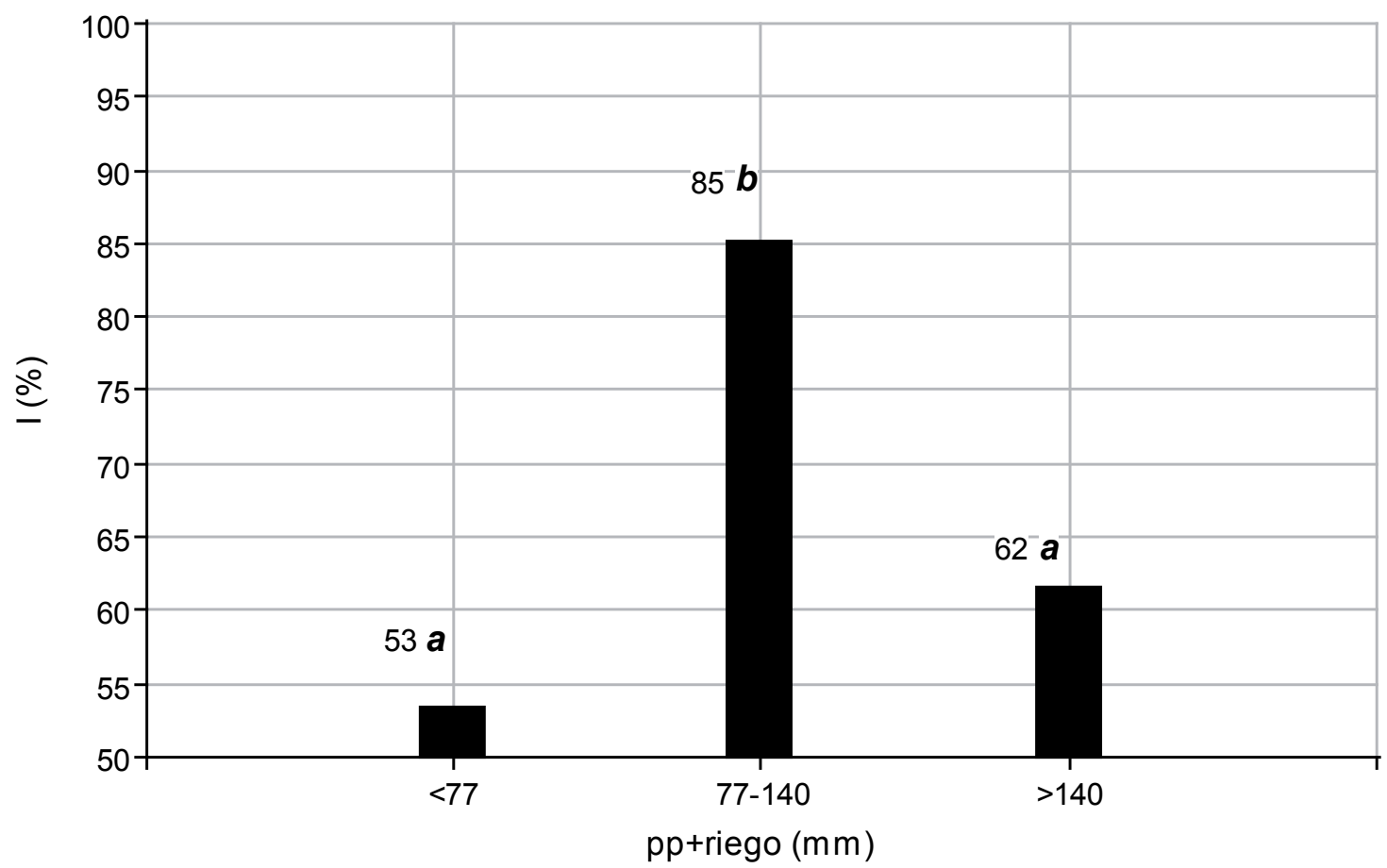

Figura 4. Variación de la incidencia (I expresada en \%) del complejo viral del achaparramiento de la alfalfa según los aportes hídricos al cultivo, en ambas localidades. Referencias: incidencia (I); precipitaciones (pp) o pp+riego. Letras diferentes indican diferencias significativas de acuerdo al test LSD Fisher $(p<0.05)$

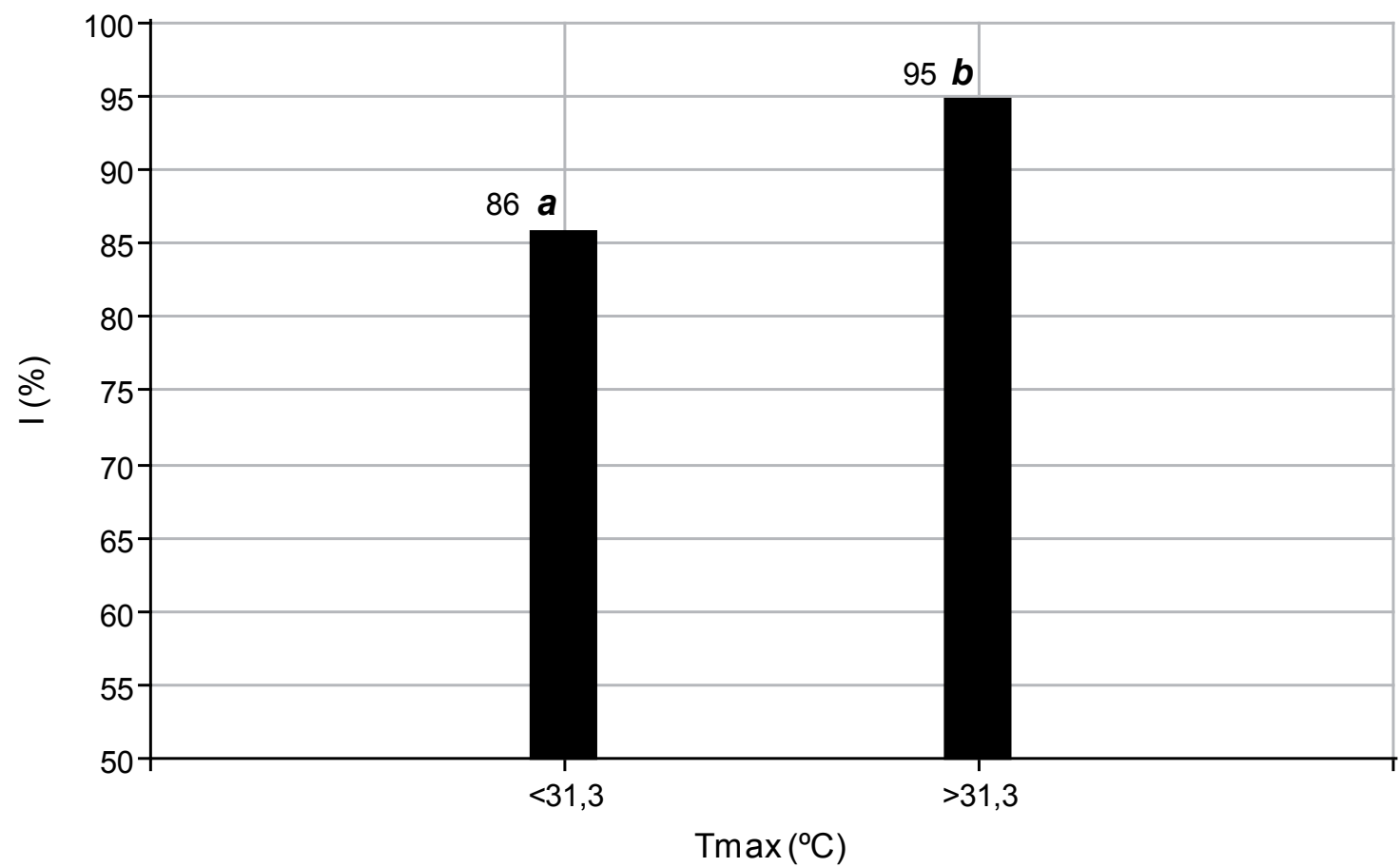

Figura 5. Variación de la incidencia (l expresada en \%) del complejo viral del achaparramiento de la alfalfa según la temperatura máxima, en ambas localidades. Referencias: incidencia (I); temperatura máxima (Tmax). Letras diferentes indican diferencias significativas de acuerdo al test LSD Fisher $(p<0.05)$ 


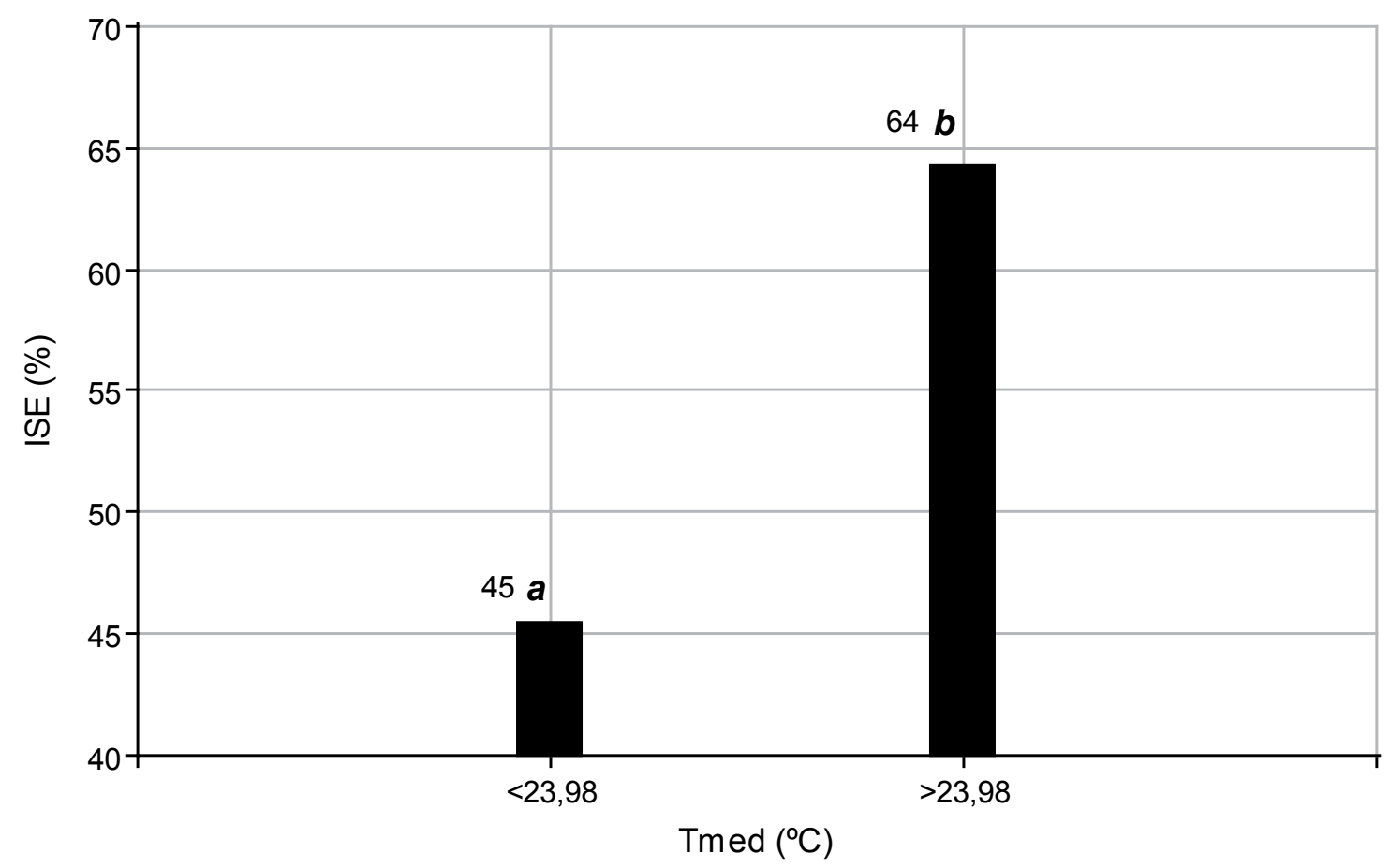

Figura 6. Variaciones del índice de severidad (ISE expresado en \%) del complejo viral del achaparramiento de la alfalfa según la temperatura media, en ambas localidades. Referencias: índice de severidad (ISE); temperatura media (Tmed). Letras diferentes indican diferencias significativas de acuerdo al test LSD Fisher $(p<0.05)$.

aumento en la susceptibilidad de las plantas a las infecciones virales y, como ya se ha mencionado, alteran la tasa de multiplicación de los virus y el movimiento sistémico de cada virus individual en una infección múltiple (Jones, 2016).

El pulgón negro de las leguminosas causa ataques importantes a la alfalfa de manera no muy frecuente o, en otras palabras, el umbral de daño económico es superado solo esporádicamente. Esto ha llevado a que en Argentina no se haya priorizado la implementación de la selección de genotipos resistentes, como sí se ha hecho con otras especies de pulgones.

\section{Dinámica en cada localidad de la incidencia y severidad relacionadas con las variables climáticas}

Se analizó, en particular para la segunda y la tercera temporada productiva en Manfredi y en Santiago del Estero, respectivamente, la relación entre la I y el ISE con la Tmed, la Tmax y la precipitación acumulada entre cortes (Figuras 7 y 8). Como se señaló anteriormente, en estas dos temporadas mencionadas se registraron los mayores porcentajes de I e ISE en cada localidad. Durante el primer año se registraron en ambas localidades las menores manifestaciones de la enfermedad, debido al tiempo necesario entre la infección y la subsiguiente aparición de los síntomas. En la EEA Manfredi (Figura 7) se observa que la evolución, tanto de la I como del ISE, siguió la misma tendencia que las precipitaciones (pp). A medida que las pp aumentaban, también lo hicieron la I y el ISE; por el contrario, ambos parámetros disminuyeron cuando las pp fueron menores. Con respecto a las temperaturas, la I y el ISE aumentaron hasta ciertos valores de Tmax y Tmin; no obstante, cuando las temperaturas siguieron aumentando, ambos parámetros disminuyeron; finalmente, cuando las temperaturas tendieron a disminuir, la I y el ISE se incrementaron.

Por el contrario, en Santiago del Estero la relación no fue tan clara, al menos para ciertos períodos. Según se muestra en la Figura 8, a pesar de incrementarse la Tmax desde $20{ }^{\circ} \mathrm{C}$ en julio hasta $37^{\circ} \mathrm{C}$ en febrero, los valores de I se mantuvieron altos y superiores a $92 \%$, si bien con ciertas fluctuaciones. En abril, la incidencia de la enfermedad disminuyó al igual que la severidad, de manera 


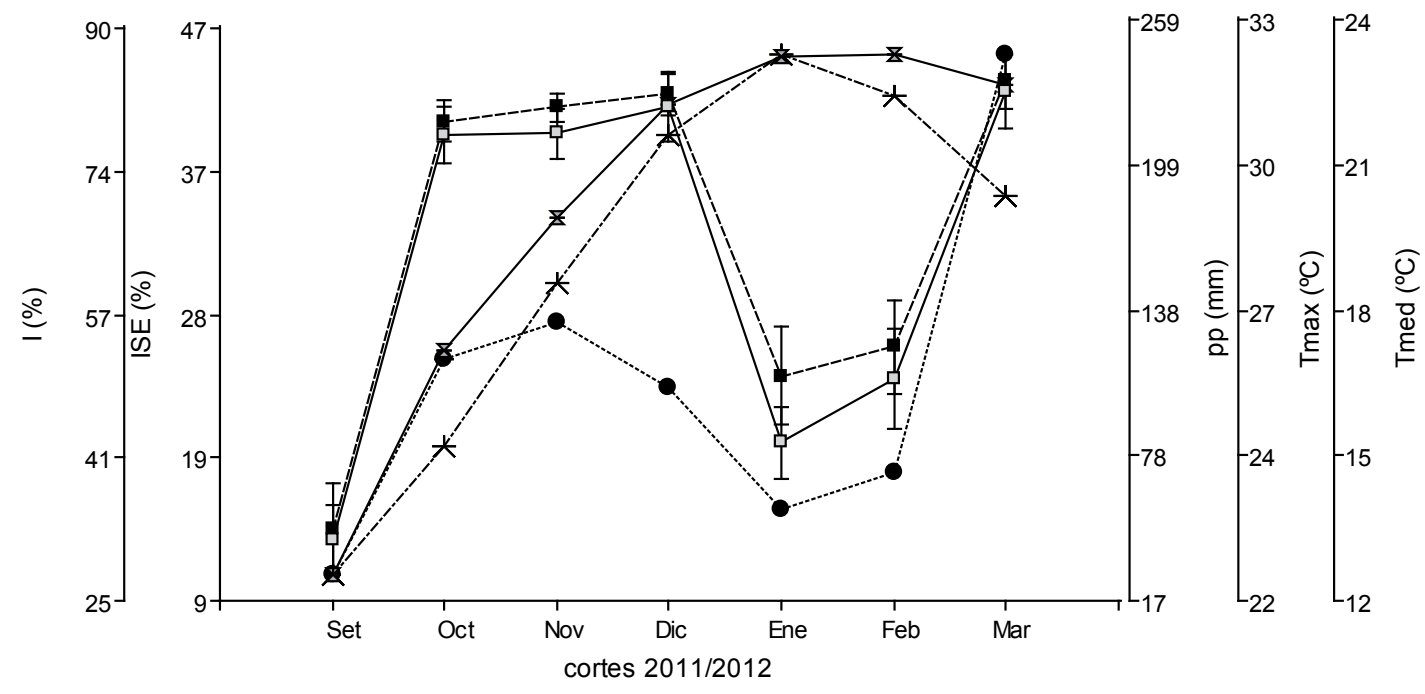

Figura 7. Precipitaciones y temperaturas (Tmax y Tmed) durante la segunda temporada productiva en la EEA Manfredi y su relación con los valores medios de I e ISE.

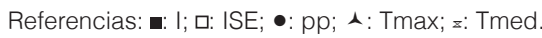

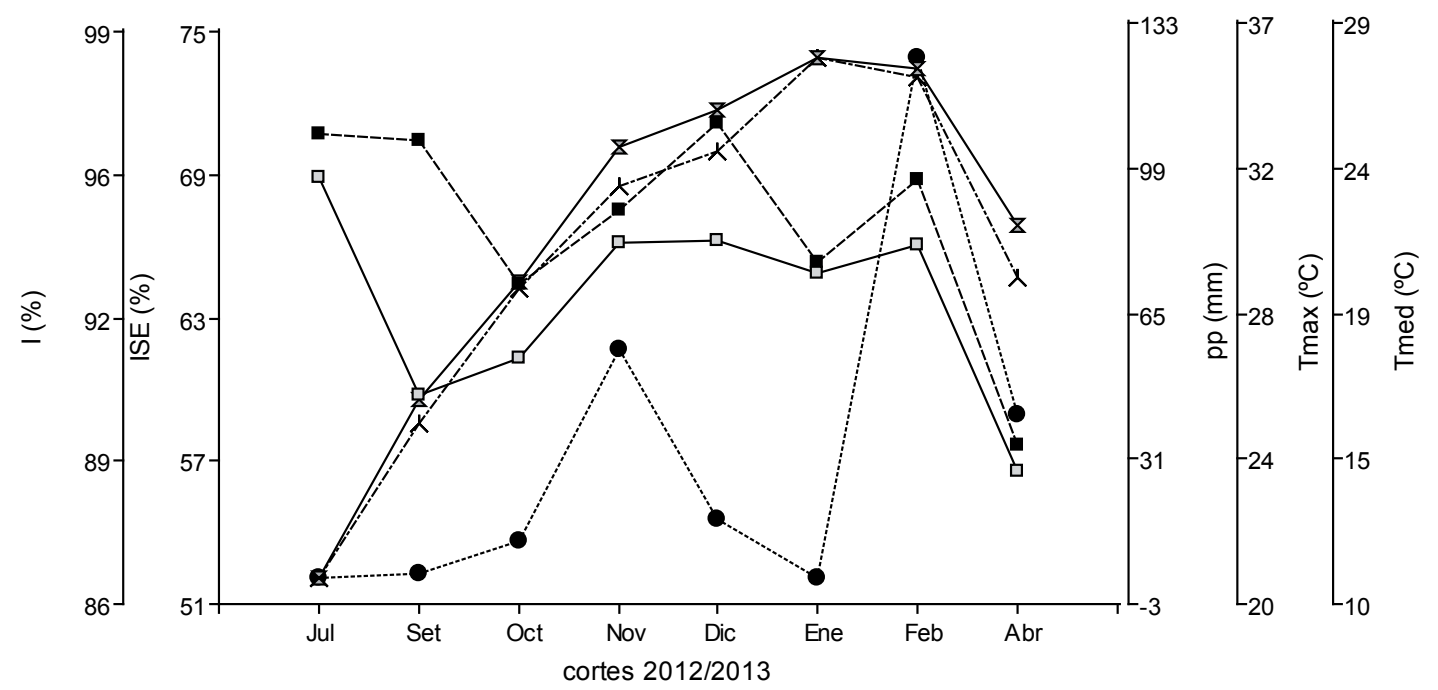

Figura 8. Precipitaciones y temperaturas (Tmax y Tmed) durante la tercera temporada productiva en la EEA Santiago del Estero y su relación con los valores medios de I e ISE.

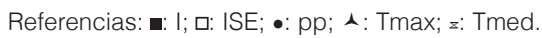

coincidente con disminución de las $\mathrm{T}^{\circ} \mathrm{C}$. La curva de la evolución de la I no siguió los cambios de pp+riego como se observó en la Figura 7. Períodos de temperaturas medias elevadas y bajas precipitaciones sin aporte de agua de riego, como en enero 2013, generaron menores tasas de crecimiento del cultivo (datos de producción por corte no mostrados) y, por ende, menor manifestación de la I.

Las diferencias observadas tanto de incidencia y severidad de la enfermedad como de producción forrajera entre los cultivares, y entre plantas dentro de cada cultivar, evidencian la existencia de variabilidad genética en los materiales estudiados. Esto avala la factibilidad de implementar un programa de mejoramiento a través de la selección de genotipos resistentes y su posterior cruzamiento para la obtención de materiales con mayores niveles de resistencia a la enfermedad del 
achaparramiento de la alfalfa. Por otro lado, y en forma complementaria, sería conveniente también seleccionar por resistencia de la alfalfa a los vectores del complejo viral.

\section{BIBLIOGRAFÍA}

Agrios, G. N. (2005). Plant Pathology. Elsevier Academic Press, London.

Alliot, B., Giannotti, J. y Signoret, P. A. (1972). Mise en évidence de particules bacilliformes de virus associés à la maladie à énations de la Luzerne (Medicago sativa L.). C. R. Acad. Sci. Paris, serie D. 274:1974-76.

Alliot, B. y Signoret, P. A. (1972). La maladie à énations de la luzerne, une maladie nouvelle pour la France. Phytopath. Z, 74:69-73.

Angueira, C. y Zamora, E. (2007). Carta de suelos. Oeste del Área de Riego del Río Dulce, Santiago del Estero, Argentina. Serie informes técnicos EEASE N ${ }^{\circ} 40$. INTA.

Aragón, J. y Imwinkelried, J. (2007). Manejo integrado de plagas de la alfalfa. En Basigalup, D. (Ed.), El cultivo de la alfalfa en la Argentina. Argentina, INTA. p. 167194.

Bar-Joseph, M., Marcus, R., y Lee, R. F. (1989). The continuous challenge of citrus tristeza virus control. Annual Review of Phytopathology, 27(1), 291-316.

Bejerman, N., Claudia, N.; Giolitti, F.; de Breuil, S.; Kitajima, E.; Pérez Fernández, J.; Basigalup, D.; Cornacchione, M. y Lenardón, S. (2011). First report of a rhabdovirus infecting alfalfa in Argentina. Plant Dis, 95, p.771.

Bejerman, N., Giolitti, F., de Breuil, S., Trucco, V., Nome, C., Lenardón, S., y Dietzgen, R. G. (2015). Complete genome sequence and integrated protein localization and interaction map for alfalfa dwarf virus, which combines properties of both cytoplasmic and nuclear plant rhabdoviruses. Virology, 483: 275-283.

Bejerman, N., Giolitti, F., Trucco, V., de Breuil, S., Dietzgen, R. G. y Lenardón, S. (2016). Complete genome sequence of a new enamovirus from Argentina infecting alfalfa plants showing dwarfism symptoms. Archives of Virology (DOI 10.1007/s00705-016-2854-3).

Bejerman, N., Giolitti, F., Trucco, V., de Breuil, S., Rodriguez Pardina, P. y Lenardón, S. (2017). Caracterización genómica del Alfalfa leaf curl virus, un capulavirus que infecta el cultivo de alfalfa en Argentina. IV Congreso Argentino de Fitopatología, Mendoza, Argentina. p. 276.

Blattny, C. (1959). Virus papillosity of the leaves of Lucerne. Folia Microbiol., 4:212-215.

Cook, A. A. y Wilton A. C. (1984). Alfalfa enation virus in the Kingdom of Saudi Arabia. FAO Plant Prot. Bull., 32
(4), 139-140.

Delgado Enguita, I. y Calvo, L. L. (1992). Incidencia de las Virosis Mosaico y "Enations" en plantas asiladas de alfalfa. Pastos, XXII (1), 85-92.

Di Rienzo J. A., Casanoves F., Balzarini M. G., Gonzalez L., Tablada M. y Robledo C. W. (2013). InfoStat, versión 2013, Grupo InfoStat, FCA, Universidad Nacional de Córdoba, Argentina. URL http://www.infostat.com.ar

Gieco, J., Moreno, M. V. y Basigalup, D. (2007). Enfermedades de la alfalfa y abordaje molecular de la selección por resistencia. En Basigalup, D. (Ed.), El cultivo de la alfalfa en la Argentina. Argentina, INTA. p. 451-475.

Grau, C. R., Radke, V. L.y Gillespie, F. L. (1982). Resistance of soybean cultivars to Sclerotinia sclerotiorum. Plant Dis., 66:506-508.

INTA-SMAGyRR. (1987). Carta de suelos de la República Argentina. Hoja Oncativo. Córdoba. Instituto Nacional de Tecnología Agropecuaria. - Secretaria Ministerio de Agricultura Ganadería y Recursos Renovables.

Jones, R.A.C.(2014). Plantvirusecologyandepidemiology: historical perspectives, recent progress and future prospects. Annals of applied biology, 164(3), 320-347. (2016). Future Scenarios for Plant Virus Pathogens as Climate Change Progresses. Advances in Virus Research, 95, 87-147.

Kalu, B. A. y Fick, G.W. (1983). Morphological stage of development as a predictor of alfalfa herbage quality. Crop Science, 23, 1167-1172.

Leclant, F., Alliot, B. y Signoret P. A., (1973). Transmission et épidemiologie de la maladie a énations de la luzerne (Lev). Primiers Résultats. Ann. Phytopathol., 5(4), 441-445.

Lenardón, S., Basigalup, D. y Pérez Fernández, J. (2010). Una virosis limitante del cultivo de alfalfa en Argentina. Informe técnico. Argentina, INTA.

Marble, V. L. (1989). Fodders for the Near East: Alfalfa. FAO Plant Production and Protection Paper, 97(1).

Mena Adriano, J. D. y Ríos, J. J. (2010). Virus (virus patogénicos). México: Universidad Autónoma de Sinaloa. Recuperado en mayo de 2016, de http://www.slideshare.net/themena1/manual-de-virus-virus-fitopatgenos-5039306

Pontis Videla, R. E. (1975). Virosis. Universidad Nacional de Cuyo, Mendoza. Facultad de Ciencias Agrarias. Hemisferio Sur.

Raman, K. V. (1986). Transmisión de Virus de papa por áfidos. Centro Internacional de la Papa (CIP), Boletín de Información Técnica, 2, p. 23.

Rodriguez Sardiña, J. y Novales Lafarga, J. (1973). Una virosis de la alfalfa con producción de "enations". An. INIA/Ser. Prt. Veg., 3, 131-146. 
Signoret, P. A., Alliot, B. y Leclant, F. (1971). Virus diseases of alfalfa and sorghum in the sourthern France. Plant Virology proceedings, $7^{\text {th }}$ Conference of the Czechoslovak Plant Virologist, High Tatras.

Smith, K. (1972). A texbook of plant virus diseases. Nueva York-Londres, Academic Press.

Stakman, E. C. y Harrar, J. G. (1968). Principios de patología vegetal. Buenos Aires, Eudeba.

Trucco, V., de Breuil, S., Bejerman, N., Lenardón, S. y Giolitti, F. (2014). Complete nucleotide sequence of Alfalfa mosaic virus isolated from alfalfa (Medicago sativa L.) in Argentina. Virus Genes, 48, 562-565. DOI: 10.1007/ s11262-014-1045-0.

(2016). Bean leafroll virus (BLRV) in Argentina: molecular characterization and detection in alfalfa fields. Eur. J. Plant Pathol. (DOI 10.1007/s10658-016-0899-5).

Van Baaren, J., Le Lann, C. y Van Alphen, J. J. M. (2010). Consequences of climate change for aphid-based multi-trophic systems. En Kindlmann, P., Dixon, A. F. G. y Michaud, J. P. (Eds.) Aphid Biodiversity under Environmental Change. Berlín, Springer. 55-68. 